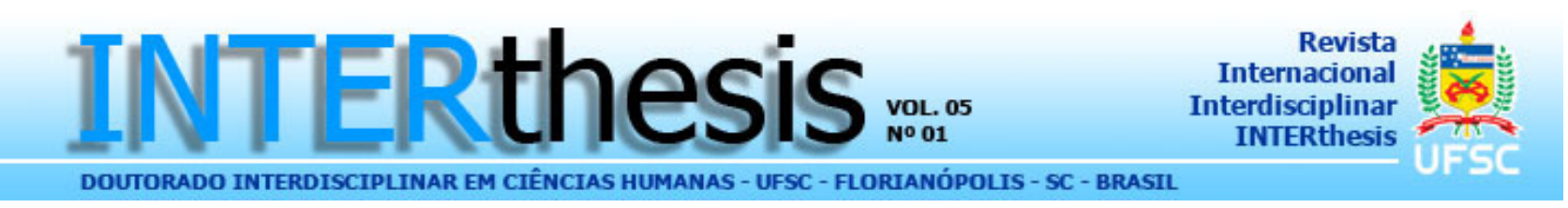

\title{
INOVAÇÕES TECNOLÓGICAS E POLÍTICAS PÚBLICAS: ANÁLISES SOCIAIS E AMBIENTAIS NO CONTEXTO DAS ATIVIDADES INDUSTRIAIS SUCROALCOOLEIRAS NO BRASIL
}

\section{TECHNOLOGICAL INNOVATIONS AND PUBLIC POLITICS: SOCIAL ENVIRONMENTAL ANALYSES IN THE CONTEXT OF SUGAR-ETHANOL INDUSTRIAL ACTIVITIES IN BRAZIL}

\section{INNOVACIONES TECNOLÓGICAS Y POLÍTICAS PÚBLICAS: ANÁLISIS SOCIALES Y AMBIENTALES EN EL CONTEXTO DE LAS ACTIVIDADES INDUSTRIALES SUCROALCOOLEIRAS EN EL BRASIL}

\begin{abstract}
"O novo cenário que surge no horizonte ainda está semiencoberto pelas ruínas do antigo mundo em decadência... e ninguém pode saber quais das antigas instituições sobreviverão e quais, no final, afundarão de vez".

"The new scenery that appears in the horizon has still been partly hidden by the ruins of the old world in decadence... and nobody can know for sure which of the old institutions will survive and which, in the end, will definitely disappear".
\end{abstract}

"La nueva escena que aparece en el horizonte mitad-es ocultada por las ruinas del viejo mundo en decaimiento...

e nadie puede saber cuáles de las viejas instituciones sobrevivirán y cuáles, en el extremo, se hundirán de vez".

(Alexis de Tocqueville)

\author{
Charlene Maria C. de Ávila Plaza ${ }^{1}$ \\ Nivaldo dos Santos ${ }^{2}$ \\ Viviane Romeiro ${ }^{3}$
}

\footnotetext{
${ }^{1}$ Mestre em Direito na área de Integração e Relações Empresariais pela Universidade de Ribeirão Preto - UNAERP-SP. Professora da Universidade Paulista -UNIP e Faculdades Objetivo - ASSBES/IUESO -GO.Pesquisadora do Núcleo de Patentes e Transferência de Tecnologia-NUPATTE-GO. Pesquisadora da Rede Ibero Americana de Propriedade Intelectual e Gestão da Inovação. E.mail: charlene plaza@hotmail.com

${ }^{2}$ Doutor em Direito pela Pontifícia Universidade Católica de São Paulo-PUC-SP. Professor Doutor UFG/UCG.

Coordenador Geral do Núcleo de Patentes e Transferência de Tecnologia-NUPATTE-GO. Coordenador do Programa de Pós-Graduação Stricto Sensu em Direito, Relações Internacionais e Desenvolvimento-UCG-GO. E.mail: nivaldo@ucg.br

${ }^{3}$ Mestranda em Planejamento do Sistema Energético-UNICAMP-SP. Coordenadora do Núcleo de Patentes e

Transferência de Tecnologia - NUPATTE-GO. Pesquisadora da Rede Estadual de Propriedade Intelectual e Gestão da
} 


\section{RESUMO}

Visa o presente artigo discutir a importância das inovações tecnológicas como propulsoras do desenvolvimento econômico das nações, bem como o papel das políticas públicas voltadas para os agentes socioeconômicos e institucionais que fazem parte da cadeia produtiva e inovativa do país. Procuramos analisar o setor sucroalcooleiro e suas conseqüências no que concerne aos aspectos ambientais enfatizando o Estado de Goiás e o bioma Cerrado. Nos aspectos sociais demonstramos a necessidade de conciliar desenvolvimento econômico com sustentabilidade ambiental e social, para propiciar um meio ambiente saudável e melhoria das condições de trabalho e vida para os cidadãos que desempenham as funções de cortadores de cana deste setor. Importante destacarmos que o artigo não tem como intuito desmerecer ou subestimar as práticas econômicas das empresas sucroalcooleiras, mas analisar certos aspectos concernentes ao meio ambiente e ao fator social para que sejam implementadas políticas consistentes que promovam sustentabilidade equilibrada com responsabilidades e comprometimentos empresariais e governamentais aliados ao tripé: economia, meio ambiente e sociedade.

Palavras-chave: Inovação Tecnológica; Políticas Públicas; Desenvolvimento Sustentável; Setor Sucroalcooleiro; Biocombustíveis

\section{ABSTRACT}

The present article aims at discussing the importance of the technological innovations as propellers of the economic development of the nations as well as the role of the public politics directed toward the socioeconomics and institutional agents who are a part of the productive and innovative chain of the country. We try to analyze the sugar-ethanol sector and its consequences concerning the environmental aspects, being emphasized the State of Goiás and the "Cerrado" bioma. In the social aspects, we demonstrate the necessity to conciliate economic development with social-environmental sustainability, to propitiate a healthy environment and improvement of the working conditions and life for the citizens who perform the functions of sugar cane cutters of this sector. It is important to emphasize that the article does not intend to underestimate the economic practices of the sugarethanol companies, but to analyze certain aspects concerning the environment and the social factor, so that consistent politics is implemented in order to promote sustainability, balanced with enterprise and governmental responsibilities and commitments allied to the tripod: economy, environment and society.

Key-words: Technological innovation; Public Politics; Sustainable Development; Sugarethanol Sector; Biofuels

\section{RESUMEN}

Tiene como objetivo el actual artículo discutir la importancia de las innovaciones tecnológicas como propulsoras del desarrollo económico de las naciones, bien como el papel de la política pública dirigida para los agentes socio-económicos y institucionales que son parte de la cadena productiva e innovadora del país. Buscamos analizar el sector sucroalcooleiro y sus consecuencias con respecto a los aspectos ambientales que son acentuados el Estado de Goiás y del bioma cerrado. En los aspectos sociales demostramos la necesidad de conciliar el desarrollo económico con la sustentabilidad ambiental y social, para ofrecer condiciones ambientales saludables y mejores condiciones de trabajo y vida para los ciudadanos que desempeñan las funciones de

Inovação e da Rede Ibero Americana de Propriedade Intelectual e Gestão da Inovação. E-mail: viviromeiro@hotmail.com

R. Inter. Interdisc. INTERthesis, Florianópolis, v.5, p.1-28, jan./jul. 2008. 
corte del bastón de azúcar de este sector. Importante destacar que el artículo no tiene como intención desmerecer o subestimar las practicas económicas de las compañías del sector, pero analizar ciertos aspectos concernientes al ambiente y al factor social para poner en ejecución políticas constantes para la promoción de una sustentabilidad equilibrada con responsabilidad y comprometimientos empresariales y gubernamentales al trípode: economía, ambiente y sociedad.

Palabras-clave: Innovación tecnológica; Política pública; Desarrollo Sostenible; Sector de Sucroalcooleiro; Biocombustibles

\section{INTRODUÇÃO}

A revolução na economia e o avanço do conhecimento trazem mudanças importantes no cenário global, fortalecendo a competitividade aplicada à inovação tecnológica. Esta, por ser um processo multidisciplinar envolve mais que simples mudanças em tecnologias. Engloba conexões, interações e influências de vários graus e setores da cadeia produtiva, incluindo relacionamentos entre empresas, entre elas e centros de pesquisa, entre universidades e empresas e entre empresas e governo.

Com os novos padrões tecnológicos busca-se uma interação entre estratégias de governo, investidores, empresas, pesquisa e desenvolvimento em busca do aperfeiçoamento dos mecanismos de estímulo à inovação no país, com duplo objetivo: aumentar a produtividade das empresas para que possam ter capacidade igualitária na competição global através da inovação tecnológica e contribuir para renovar e fortalecer o meio ambiente auxiliando na incorporação de valores éticos e responsabilidades socioambientais para todos os agentes da cadeia produtiva e para a sociedade em geral.

A realidade nacional demonstra a necessidade de iniciativas que implementem as bases de inovações tecnológicas visando atender os mercados nacionais e internacionais capazes de definir uma política de objetivos claros e mensuráveis com o poder de propiciar o desenvolvimento econômico e o bem estar social, aliando ciência, tecnologia e inovação com iniciativas políticas de prospecção inovativa e de maior eficiência política voltadas para o fortalecimento dos ambientes institucionais.

Apesar do processo de industrialização brasileira ser recente comparada com os países desenvolvidos, a nossa inovação ainda é marginal e suas políticas pouco contribui para promover inovação nas empresas do setor privado de capital nacional.

Em específico, o setor canavieiro constituiu a mais antiga atividade econômica do Brasil. No século XVI a cultura da cana foi introduzida pelos portugueses nas terras 
tupiniquins e manteve estável economicamente até o início do século XVIII, onde a partir de então iniciou sua decadência por diversos fatores.

No século $X X$ com a modernização da agroindústria açucareira, o Brasil se manteve periférico no mercado internacional, vez que ficava adstrito somente no mercado interno e, basicamente suas exportações visavam somente o escoamento da produção doméstica excedente.

Com a revolução da década de 30 a ação do Estado sob este setor se tornou acentuada através da edição do Decreto 22.789/33 instituindo o Instituto do Açúcar e Álcool (IAA) como entidade autárquica.

De acordo com Szmrecsanyi (1997), com a economia neste setor fortemente abalada pela super produção e a queda do preço tanto interno quanto externo houve a necessidade da intervenção estatal.

Devido à forte presença estatal na economia, foi criado na década de 40 o Estatuto da lavoura canavieira (Decreto lei 3.855/41), estabelecendo normas nas relações entre as usinas e os fornecedores de cana e entre eles e os trabalhadores canavieiros.

A partir de 1950, diante da situação gravosa, o setor começou a reagir, contudo o grande impulso ocorreu nas décadas de 60 e 70.

Entretanto na segunda metade da década de 70 houve um declínio do preço do açúcar no mercado internacional juntamente com a eclosão do primeiro choque do petróleo.

Como o poderio estatal ainda era arraigado no setor, medidas emergenciais foram anunciadas na tentativa de reverter o estilo de desenvolvimento com base na dependência externa.

Estas medidas, de acordo com Furtado (1983) baseavam-se em prospecção e exploração nacional de petróleo, expansão da geração de energia primária hidráulica e desenvolvimento de programas alternativos com intuito de substituir derivados de petróleo: Proóleo, Procarvão e Proálcool. ${ }^{4}$

O Proálcool foi instituído pelo Decreto $76.593 / 75$ com uma dupla finalidade:

- expandir a produção de álcool etílico anidro, visando viabilizar o uso como matéria-prima para a indústria química e;

\footnotetext{
${ }^{4}$ Na prática o Proóleo (produção de óleos vegetais a serem utilizados em motores Dieseis) mal chegou a ser lançado e o Procarvão tropeçou desde o início com sérios obstáculos, jamais adquirindo a amplitude necessária. Restou assim, o Proalcool, que registrou espetacular sucesso. (MAGALHÃES et al, 1991).
}

R. Inter. Interdisc. INTERthesis, Florianópolis, v.5, p.1-28, jan./jul. 2008. 
como combustível adicionado à gasolina, oferecendo respaldo ao setor sucroalcooleiro para a utilização de parte da capacidade produtiva ociosa para a produção de etanol.

Na década de 80 o programa atingiu seu ápice em termos de recursos investidos e veículos a álcool até a crise de abastecimento no final daquele ano.

No período sucessivo, entre 1986 a 1990 houve a desaceleração e crise do Proálcool devido à redução dos investimentos públicos na expansão do produto e a oferta em demasia de petróleo em conseqüência da queda de preços no mercado internacional.

O desequilíbrio entre a oferta e a procura de álcool combustível fez com que o Brasil importasse o produto, gerando desconfiança no abastecimento e o aumento do preço em relação à gasolina, causando danos entre a dinâmica de produção da indústria automobilística e o consumidor de carros a álcool.

Melo (2000) aponta que a partir de 1991 ocorreu à liberação do preço do açúcar, sucessivamente em 1997 iniciou-se a desregulamentação dos preços do álcool anidro e em 1999, a liberação dos preços do álcool hidratado derivado da cana de açúcar.

Face à decorrência das situações favoráveis ao setor devido a sua desregulamentação, buscou-se a implementação de tecnologias e inovações organizacionais para tornar o açúcar e o álcool mais competitivos como também explorar os subprodutos derivados destes processos e produtos.

O novo ambiente competitivo deste setor tem conduzido as indústrias canavieiras a adotarem estratégias benéficas para o desenvolvimento econômico do país face à desregulamentação de suas atividades produtivas, mas em contrapartida os aspectos relativos a sustentabilidade ambientais e sociais ficam muito aquém, que poderiam e deveriam ser exercidos juntamente com o desenvolvimento econômico do setor.

Os objetivos do presente artigo visam analisar o potencial das tecnologias de inovação como indutoras de mudanças em todos os setores, capazes de transformar a economia de mercado, o meio ambiente em busca da sustentabilidade e a maneira de consumir com ética e responsabilidade da sociedade com a finalidade de conciliar a economia, o meio ambiente e o fator social. Foram abordadas as ausências de eficiência e eficácia das políticas públicas consistentes em fomentar a inovação nacional. Em seguida descrevemos brevemente o conceito de desenvolvimento sustentável e as celeumas existentes no campo interpretativo.

R. Inter. Interdisc. INTERthesis, Florianópolis, v.5, p.1-28, jan./jul. 2008. 
Por extensão, analisamos algumas questões sobre os fatores do atraso tecnológico nacional utilizando como referencial as normas constitucionais e infraconstitucionais para discutir com mais amplitude o papel das políticas públicas em diversos contextos.

Finalmente, enfocamos as indústrias sucroalcooleiras no que diz respeito às questões ambientais e sociais sem discutirmos seus méritos no que tange ao desenvolvimento econômico visando maior reflexão sobre o papel deste setor e os impactos resultantes das suas atividades no prisma ambiental, em especial ao Estado de Goiás e ao bioma-Cerrado e no aspecto social a situação dos trabalhadores canavieiros frente às indústrias sucroalcooleiras.

\section{AS INOVAÇÕES TECNOLÓGICAS COMO FATORES PRIMORDIAIS DE MUDANÇAS DE PARADIGMAS ESTRUTURAIS NA SOCIEDADE CAPITALISTA}

As inovações acompanham a humanidade desde as mais remotas eras da nossa história. Cada fase da sociedade compreende em mudanças e aprimoramentos tecnológicos, reestruturações dos processos produtivos, transformações econômicas, sociais e ambientais.

Transformam-se o modus operandi das percepções das relações de emprego, surgindo o trabalho não remunerado que os indivíduos realizam como prosumidores, a interconexão dos sistemas econômicos com os sistemas das economias prosumidoras e as apropriações e utilizações dos recursos naturais como forma de se buscar processos e produtos inovativos e competitivos na esfera internacional.

Mudam-se as relações da cadeia produtiva empresarial que incorporam valores éticos e responsabilidades socioambientais e as tecnologias que promovem a destruição criativa, como a nanotecnologia, biotecnologia, microeletrônica, tecnologia de informação, telecomunicações entre outras.

Como apregoou o economista Joseph Schumpeter (1988), o desenvolvimento econômico precisa de "vendavais de destruição criativa", isto é, de fortes ventos de mudanças que aniquilem tecnologias e empresas retrógradas visando abertura de caminhos para as novas opções que possam romper totalmente com que existe de antigo e obsoleto.

A substituição das tecnologias do paradigma antigo cria nova onda de invenções e inovações. Assim, quando uma mudança ocorre em um processo técnico econômico 
temos não apenas um efeito de substituição nas fronteiras criativas permitindo a emergência de novas tecnologias, como também uma mudança para outro paradigma técnico econômico, promovendo a prosperidade e a competitividade no cenário internacional.

No entanto, as inovações tecnológicas não afetam somente a economia dentro de um sistema capitalista, mas toda a sociedade, modificando a realidade econômica e social, além de dinamizarem a capacidade de acumulação de riquezas e geração de renda para uma nação.

Em uma economia competitiva que valoriza a inovação, a própria divisão e classificação do trabalho merecem novos contornos. O que no ano de 1776 Adam Smith apregoou como "a fonte que possibilita grande melhora na capacidade produtiva" ao tecer considerações sobre a divisão do trabalho, atualmente não é válida como premissa desenvolvimentista.

Primeiro porque é preciso considerar que quanto mais refinada e especializada se torna uma tarefa, mais difícil e dispendiosa será para integrá-la à cadeia produtiva, e segundo, para que a inovação possa romper literalmente com o passado e com que existia antes dela, necessário uma cultura transdisciplinar do trabalho efetuado.

Schumpeter (1982) prelecionava que a inovação tecnológica é um dos elementos mais críticos de mudanças bem como geradoras de incertezas, tanto nas relações de produção como nas relações sociais e institucionais. Segundo ele, a busca por mais lucro e pela diferenciação de desempenho das entidades econômicas ou de governo encontra na tecnologia a principal fonte.

A influência do fator econômico esta vinculada diretamente à tecnologia, pois na existência de oportunidades tecnológicas, os agentes econômicos tendem a reagir ou antecipar as mudanças nos preços e nas condições de demanda, procurando novos produtos e processos dentro dos limites tecnológicos elevando a competitividade. (DOSI et al, 1988).

Porter apud Lemos (1998) defende a idéia de que a inovação tecnológica conduzirá a empresa a ter vantagens competitivas, pois reduz os custos através da facilidade de fabricação ou simplificação de logística, aumentando a diferenciação, desenvolvendo novos produtos ou melhorando os já existentes nas suas especificações, qualidade e flexibilidade.

R. Inter. Interdisc. INTERthesis, Florianópolis, v.5, p.1-28, jan./jul. 2008. 
Entretanto, nem todas as inovações têm o condão de transformar a realidade econômica e social, principalmente quando esta inovação é considerada isoladamente aos fatores determinantes dos paradigmas tecnológicos.

Segundo Dosi et al (1988), paradigma tecnológico ${ }^{5}$ é um instrumento relevante para interpretar, ordenar e hierarquizar os diferentes âmbitos e componentes do processo de inovação tecnológica. Define-se pelo conjunto de implementos desenvolvidos e melhorados que ajudam a traduzir os caminhos da busca pela inovação.

Os paradigmas tecnológicos tendem a predominarem sobre as formas mais antigas de produção ou determinados produtos já existentes no mercado.

Em termos de mercado, se traduzem em diferentes ritmos de crescimento e dinamismo e, em termos sociais um novo paradigma pode transformar substancialmente os mesmos, seja pela localização de seus sistemas produtivos, o padrão da força de trabalho, bem como as condições de vida da sociedade, enfim, as grandes inovações redefinem o paradigma tecnológico.

Assim, a presunção lógica de que o futuro imitará o passado implica na inverdade do preceito "o que funcionou melhor no passado continuará a funcionar no futuro". Este é um dos grandes paradigmas a ser quebrados pelas grandes empresas que atuam seguindo modelos de 30 ou 40 anos atrás.

Sabemos que desde a Revolução Industrial existe um hiato entre os países desenvolvidos e os em desenvolvimento tardio no que se refere a capacidade de geração de rendas, produtividade do trabalho e investimentos em inovações tecnológicas.

Estas disparidades aumentaram principalmente no contexto das inovações tecnológicas porque o Brasil sempre foi um importador de tecnologias, fazendo com que o processo inovativos do setor industrial se caracterizasse essencialmente com a criatividade estrangeira.

No entanto, embora a passos lentos, estão emergindo no contexto nacional extraordinárias transformações, principalmente no setor privado fazendo com que o foco da inovação, antes prerrogativas de multinacionais e centros de pesquisas, se estenda para as pequenas e médias empresas, descortinando oportunidades para a criatividade e empreendedorismo neste ambiente.

\footnotetext{
${ }^{5}$ Contribuição de Dosi à teoria evolucionária com a introdução do termo "paradigma tecnológico".
}

R. Inter. Interdisc. INTERthesis, Florianópolis, v.5, p.1-28, jan./jul. 2008. 
O Brasil é considerado o $14^{\circ}$ na economia mundial, mas apesar de abrigar um parque industrial diversificado em termos comparativos com a América Latina e possuir uma infra-estrutura científica e tecnológica respeitável, ainda não conseguiu ser uma potencia tecnológica. Por que deste fiasco?

Primeiro porque os instrumentos de política governamental têm-se mostrado ineficazes, excessivamente burocratizados e conservadores, marcados pelo oportunismo e a demagogia institucional, exercendo mais a função fiscalizatória, com uma série de regulamentos, leis, decretos e portarias e concentrando pouco nas efetividades das ações de prospecção de tecnologias e geração de mecanismos de gestão flexibilizadores para os agentes envolvidos na cadeia de pesquisa e desenvolvimento.

Além deste entrave, podemos mencionar os poucos recursos direcionados a P\&D (Pesquisa e Desenvolvimento), carência de recursos humanos especializados para estas atividades, número reduzidos de patentes, sendo que a ênfase ainda reside na produção de conhecimento (papers) e não na cultura patentária.

Insuficiência de incentivos fiscais para fomentar a inovação, escassa cultura de pesquisa envolvendo setores multidisciplinares para a produção de inovação com intuito de redução de tempo, ineficácia de políticas públicas focada em dinamizar a educação e o conhecimento aplicado para melhor competitividade global, carência de maior articulação entre agências de fomento, instituições de pesquisas e órgãos públicos no sistema de CT\&I (Ciência, tecnologia e inovação).

De acordo com o WEF 2006/07 (World Economic Fórum), o Brasil não está muito confortável no que diz respeito ao índice de competitividade global quanto à eficiência econômica, restando o aviltante posto $66^{\circ}$ dentre $125^{\circ}$ países analisados.

A situação se agrava quando os dados apontam a posição de $112^{\circ}$ a $125^{\circ}$ ao analisarem os indicadores sobre as responsabilidades do Estado direcionados à tributação, qualidade dos serviços públicos, segurança, educação, saúde, qualidade da ação dos três poderes e no que tange a burocracia fiscal o país é considerado o pior do mundo com a classificação de $177^{\circ}$ lugar de acordo com a fonte ( PW\&C (Princewater Coopers, 2007).

Necessário, pois refletir que "não devemos subestimar o potencial das tecnologias como fatores diferenciais de mudanças econômicas, ambientais e sociais. Sachs apud Toffler (2007, p. 409) nos diz que "é preciso assegurar que a ciência e a tecnologia 
recebam toda atenção necessária para se concentrarem em oferecer soluções para uma ampla gama de problemas globais urgentes".

O Brasil está avançando mais rápido em desenvolvimento e competitividade que no passado, mas à distância em termos comparativos com os demais países continua a aumentar 6 .

Não poderá haver acomodações do país, sendo imperativo os desafios, a aceitação dos riscos e a criação de oportunidades advindas da união entre: inovação e diferenciação para melhor competitividade brasileira no cenário internacional.

\section{O DESENVOLVIMENTO (IN) SUSTENTÁVEL: UM HIATO EXISTENTE ENTRE INOVAÇÕES TECNOLÓGICAS E AS POLÍTICAS PÚBLICAS}

\section{O Desenvolvimento Sustentável e as Celeumas Existentes na Teoria da Interpretação}

A crença de que o mercado pode ser o responsável pela implantação da filosofia do desenvolvimento sustentável, deverá ser refletida, vez que o desenvolvimento sustentável não pode ser resumido apenas como questão restrita a políticas ambientais e tecnológicas.

Um modelo realmente sustentável deverá emergir se conseguirmos aliar as questões ambientais com os modos de produção e consumo da sociedade, mudanças ou substituições das matrizes energéticas capazes de degradar o menos possível o meio ambiente, inserção das pessoas excluídas do sistema de trabalho e implementação de políticas públicas viáveis e eficazes.

O termo desenvolvimento sustentável surgiu basicamente com o relatório da Comissão Brundtland com intuito de estabelecer uma relação harmônica entre o homem e a natureza como centro do processo de desenvolvimento. O relatório salientou que a política ambiental não deve ser vista como uma responsabilidade setorial fragmentada.

De acordo com a Comissão Mundial para o Meio Ambiente e Desenvolvimento as políticas ambientais e desenvolvimentistas tem como objetivos:

- Retomar o crescimento;

\footnotetext{
${ }^{6}$ A taxa de crescimento no Brasil (2007) foi de $5 \%$. No mesmo período à América Latina, 5,6\%, países da ex-União Soviética, 8,1\%, Índia, 8,5\% e China 11,4\%. (TROSTER, R.L., 2008).
}

R. Inter. Interdisc. INTERthesis, Florianópolis, v.5, p.1-28, jan./jul. 2008. 
- Alterar a qualidade do desenvolvimento;

- Atender às necessidades essenciais de emprego, alimentação, energia, água e saneamento;

- Manter um nível populacional sustentável;

- Conservar e melhorar a base de recurso;

- Reorientar a tecnologia e administrar o risco, e

- Incluir o meio ambiente e a economia no processo de tomada de decisões.

Mas quando tratamos de interpretar o vocábulo "desenvolvimento sustentável" várias celeumas emergem, vez que para alguns como Baroni (1992) e Lélé apud Baroni (1992) a nomenclatura diversifica idéias e reflete a falta de precisão na conceituação corrente de seu significado.

Entretanto, embora seja um termo amplamente utilizado, não existe um consenso do que seja o desenvolvimento sustentável. Para alguns significam manter o equilíbrio do crescimento econômico através do manejo mais racional dos recursos naturais com tecnologias mais eficientes e menos poluentes. Para outros o termo é eminentemente de cunho social e político ou implica novas bases, nos quais se sustenta a civilização através da construção de uma racionalidade ambiental aliando a organização social produtiva, o bem estar material do ser humano e o desenvolvimento espiritual como qualidade de vida.

A sua interpretação provoca diversidade nos conceitos gerando um desequilíbrio do tripé da sustentabilidade que engloba: crescimento econômico, preservação ambiental e equidade social.

Qualquer que seja a predominância destes eixos norteadores da sustentabilidade não será viável, pois o equilíbrio se torna essencial para atingirmos o tão almejado desenvolvimento sustentável, por vezes sucumbido pelo predomínio de interesses excusos em detrimento dos interesses da humanidade.

\section{Análises do Papel das Políticas Públicas no Contexto das Inovações Tecnológicas: Aspectos Constitucionais e Infra Constitucionais}

Vivemos a era da economia do conhecimento com significativas transformações no cenário global cuja velocidade não linear da informação tem fortalecido a competitividade das políticas empresariais no que se refere à capacidade de geração e criação de inovações.

R. Inter. Interdisc. INTERthesis, Florianópolis, v.5, p.1-28, jan./jul. 2008. 
Entretanto, uma economia baseada em conhecimento e inovação desafia não apenas os economistas, mas a própria economia em si principalmente se o país carece de instrumentos norteadores para melhor desenvolver economicamente, ambientalmente e socialmente ou ainda não possui uma cultura voltada à valoração dos bens intangíveis.

Boisot apud Toffler (1998, p.145) analisa que "quando a informação deixa de desempenhar um papel de coadjuvante para tornar o foco principal das transações econômicas, a lógica que regula a produção e troca de bens tangíveis deixa de ser aplicável". Afirma que a economia não é uma ciência exata e os bens da informação e do conhecimento não tem um valor fixo e determinado exigindo uma abordagem distinta na economia do conhecimento.

O uso criativo do conhecimento capaz de gerar novos produtos, processos e serviços mediante a inovação tecnológica, requerem ferramentas adequadas, dentre elas, cooperação entre universidades, empresas, governos e organizações não governamentais com intuito e alavancar o investimento privado, aumentar e intensificar a capacidade produtiva e a inventiva nacional.

Neste contexto, a atividade de inovação para ser satisfatória no país, deverá contar com políticas públicas claras e mensuráveis capazes de promover o progresso econômico e o bem estar social juntamente com a ciência e a tecnologia, principalmente visando à competitividade no cenário internacional.

A inovação pode ser considerada condição sine qua non para a competitividade global das empresas e da economia nacional, entretanto as políticas públicas no país são insatisfatórias e não conseguem criar um ambiente favorável à atividade inovativa capazes de competir pari passu, internacionalmente.

No que tange as universidades, o Estado ainda exerce um papel fiscalizador e regulador em demasia, criando um descompasso com os preceitos normativos do artigo $218^{7}$ reforçado pelo artigo $207^{8}$, da Constituição Federal que primam em regular a

\footnotetext{
${ }^{7}$ Art 218. O Estado promoverá e incentivará o desenvolvimento científico, a pesquisa e capacitação tecnológica.

$\S 1^{\circ} \mathrm{A}$ pesquisa científica básica receberá tratamento prioritário do Estado, tendo em vista o bem público e o progresso da ciência.

$\S 2^{\circ} \mathrm{A}$ pesquisa tecnológica voltar-se-á preponderantemente para a solução dos problemas brasileiros e para o desenvolvimento do sistema produtivo nacional e regional.

$\S 3^{\circ} \mathrm{O}$ Estado apoiará a formação de recursos humanos nas áreas de ciência, pesquisa e tecnologia, e concederá aos que delas se ocuparem meio e condições especiais de trabalho.

$\S 4^{\circ} \mathrm{A}$ lei apoiará e estimulará as empresas que invistam em pesquisa, criação de tecnologia adequada ao país, formulação e aperfeiçoamento de seus recursos humanos e que pratiquem sistema de remuneração
}

R. Inter. Interdisc. INTERthesis, Florianópolis, v.5, p.1-28, jan./jul. 2008. 
competência estatal voltada à prospecção e ao incentivo ao avanço científico, tecnológico e administrativo bem como a gestão patrimonial e financeira das mesmas.

Assegura a Constituição Federal duas espécies de pesquisa: científica e tecnológica. A pesquisa científica básica receberá tratamento prioritário do Estado, tendo em vista o bem público e o progresso da ciência. Já a pesquisa tecnológica deverá estar direcionada preponderantemente para a solução dos problemas brasileiros e para o desenvolvimento do sistema produtivo nacional e regional.

No contexto atual, o papel das políticas públicas com intuito de estreitar as relações empresas/universidades significa avanços na economia á partir do momento que haja um compromisso político com o sistema nacional de inovação e os processos de transferência de tecnologia, isto é, a empresa investindo recursos nas pesquisas e as universidades desenvolvendo-as.

Com o advento da Lei de Inovação (Lei n. 10.973/2004), o ajuste implementado pela indústria nacional continuou a não privilegiar o desenvolvimento tecnológico como forma de elevar a competitividade e superar as barreiras do subdesenvolvimento tecnológico.

Há uma baixa propensão das empresas a realizar investimentos, característica estrutural dos sistemas científicos brasileiros, relacionados aos escassos incentivos fiscais à inovação. Baixa cultura de propriedade intelectual, poucos mecanismos permanentes de financiamentos, relação não linear entre universidades e empresas e desconexão entre os interesses sociais e pesquisas no âmbito das universidades/empresas e centros de pesquisas.

O artigo $9^{\circ}$, item $2^{\circ}$, da referida lei, ao aludir o contrato (propriedade intelectual da criação) não se referiu de forma eficiente para assegurar de modo absoluto a eficácia da proteção à propriedade intelectual, apregoando que:

Art $9^{\circ}$ É facultado á ICT celebrar acordos de parceria para realização de atividades conjuntas de pesquisa científica e tecnológica e

que assegurem ao empregado, desvinculada do salário, participação nos ganhos econômicos resultantes da produtividade de seu trabalho.

$\S 5^{\circ}$ É facultado aos Estados e ao Distrito Federal vincular parcela de sua receita orçamentária a entidades públicas de fomento ao ensino e á pesquisa científica e tecnológica.

${ }^{8}$ Art 207. As universidades gozam de autonomia ditático-científica, administrativa e de gestão e patrimonial, e obedecerão ao princípio de indissociabilidade ente ensino, pesquisa e extensão.

R. Inter. Interdisc. INTERthesis, Florianópolis, v.5, p.1-28, jan./jul. 2008. 
desenvolvimento de tecnologia, produto ou processo, com instituições públicas e privadas.

(...).

$\S 2^{\circ}$ As partes deverão prever, em contrato, a titularidade da propriedade intelectual e a participação nos resultados da exploração das criações resultantes da parceria, assegurando aos signatários o direito ao licenciamento, observado o disposto nos $\S \S 4^{\circ}$ e $5^{\circ}$ do art. $6^{\circ}$ desta Lei.

Neste prisma, omisso à matéria é o artigo $11^{\circ}$ no que tange aos prazos para que a cessão seja concretizada, ausência de definição dos prazos para preservar o mencionado direito à propriedade. De acordo com o referido artigo o ICT (Instituto de Ciência e Tecnologia), poderá ceder seus direitos sobre a criação, mediante manifestação expressa e motivada, a titulo não-oneroso, nos casos e condições definidos em regulamento, para que o respectivo criador os exerça em seu próprio nome e sob sua inteira responsabilidade, nos termos da legislação pertinente.

Outra lacuna apresentada pela lei de inovação foi a pouca atenção às pesquisas cientificas e tecnológicas, defasando-as com relação às necessidades sociais e materiais da população, e conseqüentemente, enfraquecendo-as perante política de concorrência internacional.

Portanto, ainda que seja meritória a norma contida pela supra mencionada lei, apoiando a economia do conhecimento, a constatação é que, necessita ser aperfeiçoada, para que venha a ser efetivado na prática um maior estímulo à inovação, flexibilizando as relações das instituições científicas e tecnológicas com um maior intercâmbio entre universidades e empresas, com intuito de gerar um modelo de desenvolvimento tecnológico autônomo no Brasil.

Seguramente os desenvolvimentos científico e tecnológico sobre a produção de bens e serviços, comércio internacional, crescimentos econômico e social devem ser focados nos seguintes pressupostos:

- Na P\&D (Pesquisa e Desenvolvimento), com parcerias sincronizadas entre a academia e empresa.

- Nos recursos humanos (tecnologia social) qualificados, financiamentos para realização de projetos em pesquisas menos burocratizados, tendo como agentes 
promotores governos em parcerias com o setor privado para financiar e orientar esforços de P\&D.

- Finalmente, na gestão tecnológica das empresas e centros acadêmicos que incluam administração de projetos de P\&D, transferência de tecnologia para obtenção de maior assimilação e aprendizagem aos aportes dos setores envolvidos.

Deste modelo estrutural, podemos obter um grau de interesse elevado das empresas, para que adaptem às novas tecnologias, o respaldo governamental dos paradigmas inovativos, a coordenação entre políticas de fomento produtivas, difusão tecnológica e a elevação da qualificação das tecnologias sociais, estimulando a criação de novos conhecimentos.

A competição nos mercados mundiais depende cada vez mais de políticas voltadas para investimento em P\&D, difusão do progresso tecnológico e sua incorporação ao sistema econômico e produtivo, através de alianças estratégicas das comunidades nacionais e internacionais, mas com a ressalva de que sejam respeitados o nível de crescimento tecnológico e inovador de cada país.

\section{IMPACTOS SOCIAIS E AMBIENTAIS DO SETOR SUCROALCOOLEIRO: 0 DESCOMPASSO DO DESENVOLVIMENTO ECONOMICO COM A SUSTENTABILIDADE AMBIENTAL E SOCIAL}

As questões ambientais começam a ganhar espaço para maiores reflexões e estudos principalmente com o desenvolvimento das atividades agroindustriais canavieiras que empregam, lamentavelmente, o uso de métodos e substâncias massivas e nocivas ao meio ambiente bem como sobre as condições dos trabalhadores e pequenos produtores rurais a mercê do propalado desenvolvimento econômico global.

Qualquer estratégia de desenvolvimento que não traduz em seu bojo as sustentabilidades ambiental, econômica e social, trará conseqüências para o setor produtivo empresarial, para a sociedade e para o meio ambiente. Altvater (1995) preleciona que o desenvolvimento econômico e o meio ambiente deverão ter reciprocidade, porque as atividades econômicas transformam o meio ambiente e este alterado, pode constituir em restrição para o futuro, pois seus recursos são esgotáveis e a sociedade capitalista é expansiva no tempo e no espaço.

R. Inter. Interdisc. INTERthesis, Florianópolis, v.5, p.1-28, jan./jul. 2008. 
Mas esta reciprocidade até o momento não foi amplamente alcançada. $O$ uso indevido da terra e a abusiva utilização dos recursos naturais diminuem a biodiversidade causando sérios impactos ambientais e por conseqüência impactos sociais.

Ao lado dos grandes benéficos econômicos gerados pela implantação e implementação tanto a níveis nacionais como internacionais dos biocombustíveis, há o lado obscuro deste desenvolvimento.

Um dos aspectos obscuros que a agroindústria canavieira traz com suas técnicas arcaicas diz respeito aos impactos ambientais com o uso e ocupação de solo, perdas das áreas de preservação permanentes e reservas legais, queimadas, erosão e poluição dos solos pela vinhaça ou vinhoto e o que concerne a esta última prática, não há estudos avançados sobre os verdadeiros danos ambientais que provocam no solo e quiçá nos lençóis freáticos.

Nos impactos sócios econômicos podemos mencionar as condições de trabalho com o avanço da mecanização, eliminação das pequenas e médias empresas agrícolas e o êxodo rural. A migração dos trabalhadores rurais para as cidades de outros Estados traz sérias dificuldades, vez que são lugares que possuem populações entre 30 a 50 mil habitantes. Conseqüentemente, esta migração gera descontroles sociais nos municípios, criando dentre outros aspectos nocivos às comunidades que os recebem, hospitais com super lotação, intensificação da violência, incapacidade administrativa municipal para atender as demandas do crescimento populacional nos tempos sazonais das safras da cana de açúcar.

Será que ainda pactuamos com a regra do desenvolvimento econômico pelo desenvolvimento econômico, sem agregarmos fatores ambientais e sociais?

Retornamos aos tempos dos latifúndios, escravidão e monoculturas?

Em tese, sim. O modelo agro-exportador que se consolida, reforça a relação do Estado com o latifúndio canavieiro, sob a nomenclatura de agronegócio, cujos aspectos ambientais e sociais estão subjugados a segundo plano.

Atualmente o Brasil lidera o ranking mundial das exportações de etanol, estimado em 3,2 bilhões de litros comercializados no ano de 2006 devido a interesses

R. Inter. Interdisc. INTERthesis, Florianópolis, v.5, p.1-28, jan./jul. 2008. 
internacionais pelos biocombustíveis, considerados como fonte de energia ecologicamente correta ${ }^{9}$.

Apesar de ser considerado como fontes de alternativa de energias menos poluentes, a União Européia, em janeiro de 2008, irá formular novas regras de sustentabilidade ambiental com a possível adoção de quatro critérios que regula a permissividade da importação dos biocombustíveis.

Diante do cenário nada animador no que concerne às responsabilidades ambientais e sociais deste setor, as novas regras possivelmente poderão inviabilizar o crescimento das vendas dos biocombustíveis brasileiro para o Bloco Europeu. E por quê?

Primeiro, as bases da nova regra estabelecerá um biocombustível ambientalmente sustentável, isto significa que não poderá ser obtido a partir de matérias-primas cultivadas em áreas úmidas ou de florestas. Atentando que, lamentavelmente não houve inserção pelo parlamento Europeu sobre o bioma Cerrado brasileiro.

Com estas possíveis normatizações, o bloco exigirá provas de eficiência energética na produção, defesa da biodiversidade e certificação (selo de certificação), além de outras medidas, como a adoção para enquadrar a floresta tropical no intuito de coibir o desmatamento. Atitude louvável, vez que as políticas públicas nacionais se mostram ineficazes bem como a falta de comprometimento do Brasil frente às responsabilidades do Protocolo de Kyoto em assumir o papel de país poluidor, mais precisamente $04^{\circ}$ no ranking de emissões de gases de efeito estufa.

Outro critério do bloco europeu visa limitar emissões de gases de efeito estufa, compreendendo desde a produção do etanol, transporte e processamento, através do controle denominado "poupança gás" na utilização do biocombustivel.

Deste modo, as exigências irão além do processo de produção. Se houver desmatamento na produção do bioetanol, deverão ser contabilizadas as emissões provocadas pela mudança do uso de terra, inviabilizando comercialmente a sua exportação para os países componentes do bloco.

O terceiro critério concerne na proibição do bicombustível originado de matériasprimas obtidas de florestas não afetadas pelas ações antrópicas ou áreas protegidas.

\footnotetext{
${ }^{9}$ De acordo com a União da Agroindústria Canavieira de São Paulo - ÚNICA - a última safra finalizada em abril passado deverá ter um salto de 17,8 bilhões de litros para 38 bilhões de litros até 2012. Neste período, 76 novas usinas deverão se somar às 325 atualmente em operação, e as terras ocupadas com canaviais aumentarão e 6,5 milhões de hectares para 10 milhões.
}

R. Inter. Interdisc. INTERthesis, Florianópolis, v.5, p.1-28, jan./jul. 2008. 
No caso da cana-de-açúcar brasileira, há intensa probabilidade de que os combustíveis produzidos pelas agroindústrias acelerem a devastação dos ecossistemas frágeis, em especial o Cerrado e a Amazônia com a proliferação de monoculturas açucareiras. Será que o país adotará medidas preventivas e sustentáveis diante destes futuros critérios do bloco europeu para garantir que as exportações continuem economicamente viáveis? Temos nossas duvidas e o Cerrado já se encontra na zona de perigo pela forma predatória desta monocultura.

Um levantamento elaborado pelo Instituto Sociedade, População e Natureza ISPN-2007 e financiado com recursos da Comunidade Européia aponta a tendência do avanço dos canaviais no segundo bioma mais ameaçado do país. O desmatamento na região gira em torno de $1,1 \%$ ao ano, o que equivale à destruição de 22 mil $\mathrm{Km}^{2}$ por ano, maior que a degradação da Amazônia.

Assim, segundo mapa (01) a distribuição do cultivo da cana-de-açúcar no Cerrado por município e indicação das usinas instaladas e em construção.

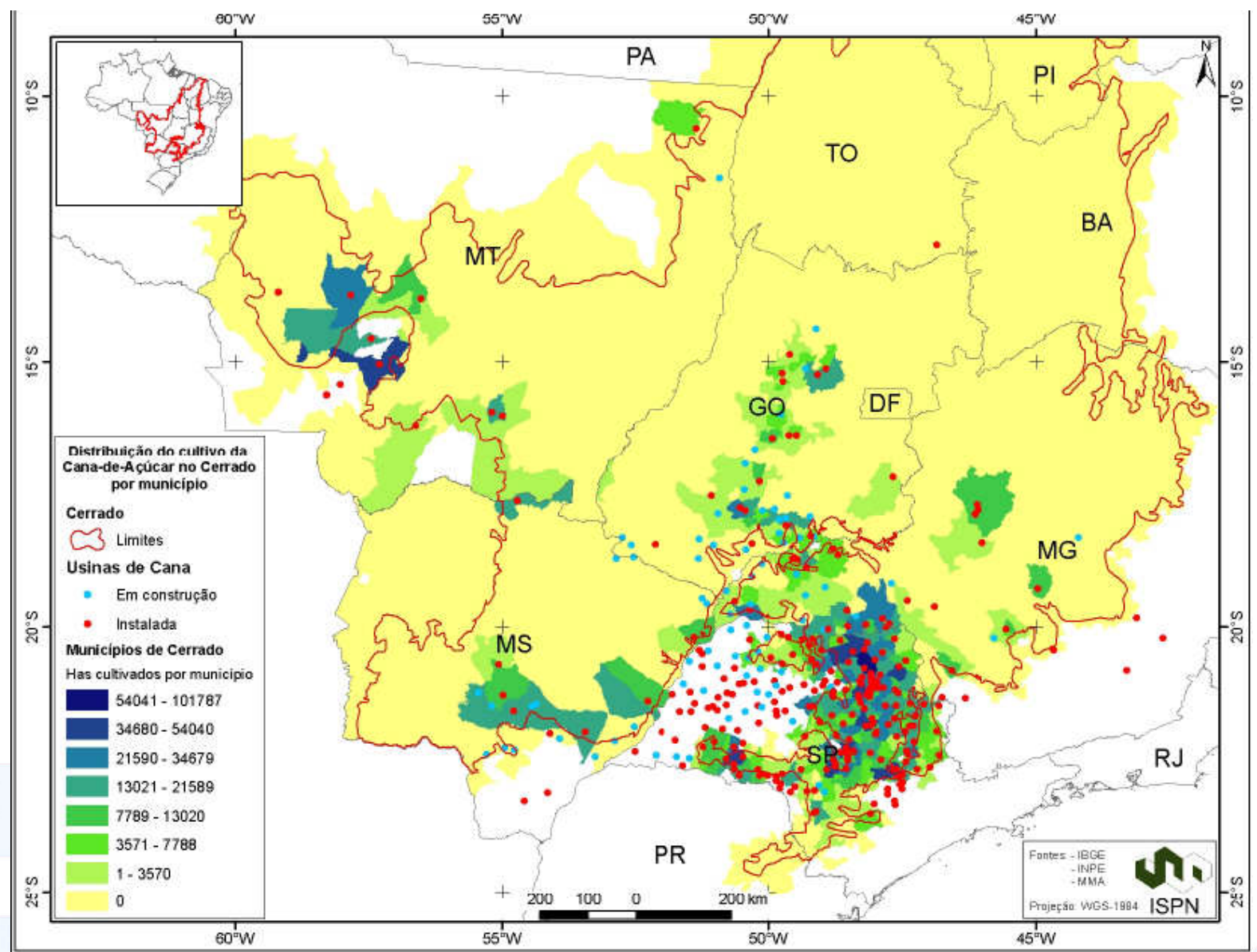

(Fonte: ISPN-Instituto Sociedade, População e Natureza, 2007). A partir dos dados do INPE/IBGE e MMA

R. Inter. Interdisc. INTERthesis, Florianópolis, v.5, p.1-28, jan./jul. 2008. 
Considerado o maior ecossistema ${ }^{10}$ do Centro-Oeste, com variedades extraordinárias de espécies da fauna e da flora brasileira, além de abrigar mananciais de água de valor inestimável, representa o bioma de região de savana mais rica em biodiversidade no mundo com risco de desaparecer até 2030.

E qual o atrativo deste ecossistema para a implantação da monocultura da cana?

A resposta plausível seria a disponibilidade de mão-de-obra barata e os terrenos planos da região. A cultura canavieira, segundo Ferreira (2006), avançou vorazmente sobre os campos de outras culturas rurais e, em semelhante intensidade, o domínio das terras destinadas ao plantio da cana passou para as usinas, por força de aquisição ou arrendamento.

O Estado de Goiás registrou entre as colheitas dos anos de 1999/2000 e 2003/2004 um aumento de 81\% na superfície utilizada pela cana-de-açúcar e, em 2006 foi responsável por 6,6\% da colheita total brasileira, (FUSER, 2007).

Nos municípios de Goianésia e Barro Alto, em Goiás, uma área de cerca de 2,5 mil Km² considerada pelo Ministério do Meio Ambiente como "prioridade muito alta para fomento e uso sustentável" já esta dominada pela cultura da cana. (ver mapa 02, abaixo).

\footnotetext{
${ }^{10} \mathrm{O}$ Cerrado é um bioma que abrigam mais de 10 mil espécies de plantas, das quais 4.400 são endêmicas, 847 espécies de pássaros e quase 300 e mamíferos. Fonte da Organização não-governamental Conservação Internacional.
}

R. Inter. Interdisc. INTERthesis, Florianópolis, v.5, p.1-28, jan./jul. 2008. 


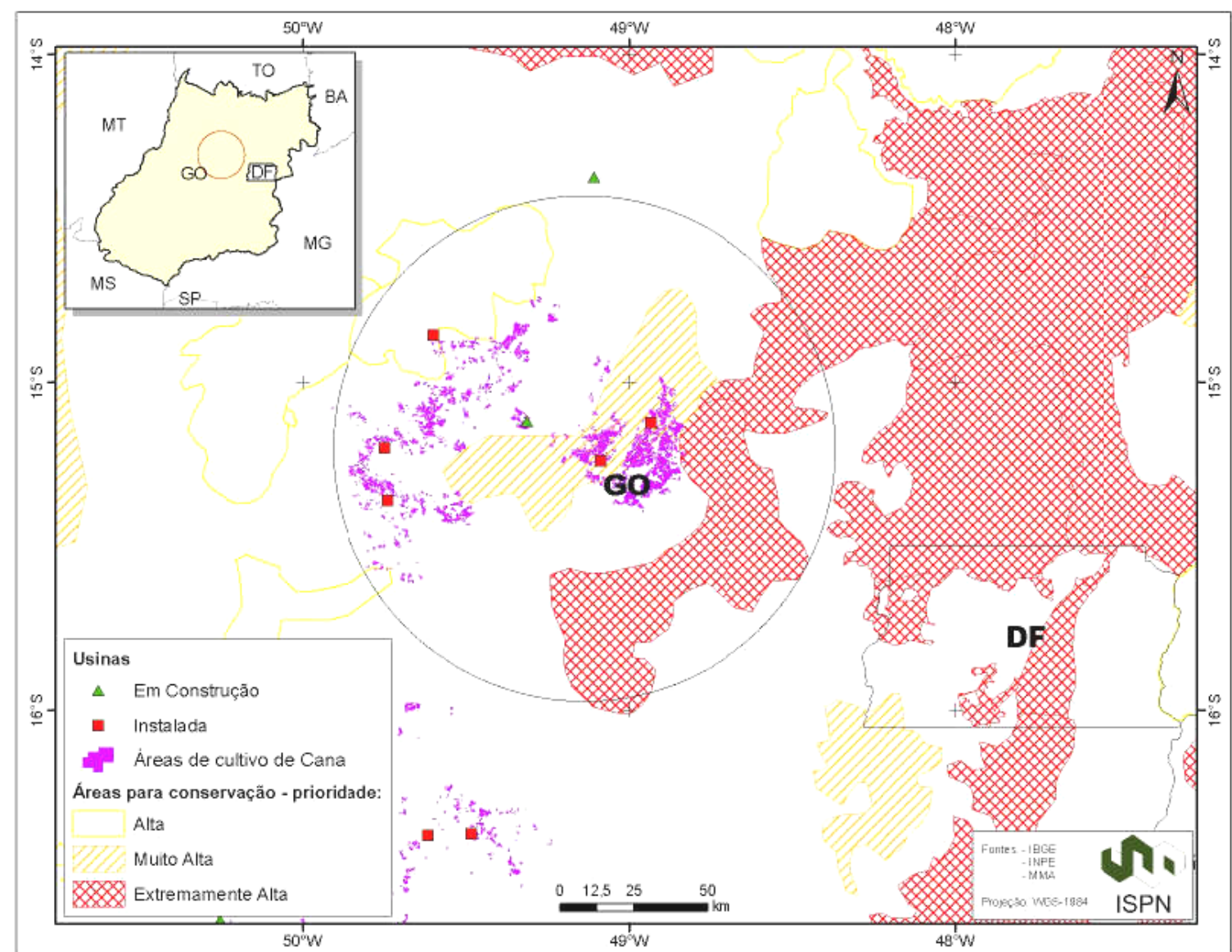

(Fonte: ISPN-Instituto Sociedade, População e Natureza, 2007). A partir dos dados do INPE/IBGE e MMA.

De acordo com um relatório técnico produzido pela Organização Conservação Internacional (2004), menciona que o Cerrado é o segundo bioma brasileiro e que juntamente com a Mata Atlântica integra um rol de 34 ambientes mais ameaçados pelas ações antrópicas. A entidade alinha 11 iniciativas polêmicas:

- Adotar uma postura de desmatamento zero para o Cerrado, pelo menos até que seja feito um planejamento integrado para a ocupação do bioma;

- Criar programas de recuperação de áreas degradadas como forma de compensar as áreas com desmatamento evitado;

- Ampliar a porcentagem das áreas de proteção integral no cerrado, que hoje não chega a 3\% o bioma, preferencialmente conciliando o aumento da proteção com a política de proteção com a política de proteção de recursos hídricos;

- Colocar em prática o zoneamento ecológico-econômico como forma de planejar a ocupação do Cerrado, atrelando seus cumprimentos e descumprimentos aos instrumentos tributários, como o Imposto Territorial Rural - ITR;

R. Inter. Interdisc. INTERthesis, Florianópolis, v.5, p.1-28, jan./jul. 2008. 
- Implementar um programa de monitoramento continuado por satélites, de forma a acompanhar o uso do solo do Cerrado;

- Estimular a manutenção e o fortalecimento socioeconômico dos núcleos de produção mais tradicionais, incentivando a diversificação de produtos em regiões ambientalmente mais sensíveis, onde os produtores rurais seriam estimulados a implantar sistemas produtivos mais adaptados às condições locais e menos impactantes, agregando valor aos produtos típicos do Cerrado;

- Cobrar a recuperação ambiental dos proprietários rurais que estão com passivos nos cumprimentos do estabelecido pelo Código Florestal;

- Elaborar mecanismos capazes de agregar valor de mercado aos produtos de regiões onde os proprietários são ambientalmente corretos;

- Priorizar a aplicação dos recursos públicos nas áreas carentes, mas que possuam uma boa cobertura vegetal ou estejam localizadas nas áreas de influência das Unidades de Conservação;

- Investir na formação de profissionais especializados em conservação da biodiversidade e de recursos hídricos, ademais de naqueles dedicados ao uso racional de componentes do Cerrado;

- Efetivar um pacto político entre Ministérios, Estados e a sociedade, de forma a implementar as ações acima. (Cl, 2004, p.09).

Outros danos podem ser mencionados dentro do panorama rural. Grandes partes das terras subentendidas como degradadas ou subaproveitáveis são pastagens arborizadas, com valores ecológicos significativos, cobertos por vegetações rasteiras que abrigam diversidade bastante rica e sofrem os impactos para ceder lugar aos canaviais.

Young e Steffen (2007) advertem para a vulnerabilidade da economia brasileira diante da ausência de respostas e soluções plausíveis para estas questões ambientais.

Analisam que se for comprovado que a produção de biocombustíveis estiver diretamente associada ao desmatamento e redução da biodiversidade, muito provavelmente que a esperada explosão na demanda externa não se concretize e o setor sucroalcooleiro entre em crise e, acrescentamos na referida análise "se aprovada às regras de sustentabilidade da União Européia em Bruxelas, esta argumentação poderá se concretizar".

R. Inter. Interdisc. INTERthesis, Florianópolis, v.5, p.1-28, jan./jul. 2008. 
Este padrão de desenvolvimento exige reflexão emergencial sobre os limites da natureza e o quanto é necessário desenvolvermos, mas sempre na busca do equilíbrio socioeconômico e ambiental, com perfeita consonância do tripé: economia, natureza e sociedade. Há riscos de pressões internacionais, caso os biocombustíveis não estiverem relacionados a métodos éticos de produção.

Existem motivos preocupantes em relação aos impactos sociais advindos com a implantação da monocultura canavieira. Evidências assinaladas por organismos internacionais (Nações Unidas e o Banco Mundial) em face aos prejuízos na produção de alimentos que agravaria a fome mundial.

Atualmente existe em torno de 1,2 milhões trabalhadores nos canaviais que não vivem em condições dignas de trabalho e moradia.

Em comparação com os dias atuais e o ano de 2004, os salários dos trabalhadores diminuíram sensivelmente e a produtividade laboral intensificou ${ }^{11}$. O trabalhador canavieiro ficou a mercê de doenças relacionadas com o esforço físico repetitivo, bem como doenças osteo-musculares.

Segundo Junqueira (2007, p. A16) “O problema é que melhorar as condições de trabalho dos cortadores de cana significa mexer no método de produção do setor sucroalcooleiro, que tem surtido resultados econômicos positivos para o empresário e o país".

Vislumbrando as situações aviltantes destes trabalhadores, o Ministério Público através das ações civis públicas, (Lei 7.347/85), luta para enquadrar os empresários sucroalcooleiros e o governo federal para que cumpram o estatuído na lei 4.870/65 nos seus artigos 35 e 36 objetivando a implementação do Plano de Assistência Social ao trabalhador e a competente fiscalização por parte da administração pública federal.

Por esta Lei os recursos de $1 \%$ do preço de saco de açúcar, $1 \%$ do preço da tonelada de cana e $2 \%$ sobre o litro de álcool são aplicados em assistência médica e educacional, financiamento de cooperativas e de culturas e subsistência nas terras utilizadas pelos trabalhadores e na promoção de programas educativos, culturais e de recreação.

\footnotetext{
${ }^{11}$ A média salarial variava entre 2 a 2 salários mínimos e meio. Atualmente, 1 salário mínimo mensal. Com relação à produtividade laboral, o trabalhador cortava 6 toneladas dia de cana e hoje a média é de 10 toneladas a $12 \mathrm{t}$ diárias.
}

R. Inter. Interdisc. INTERthesis, Florianópolis, v.5, p.1-28, jan./jul. 2008. 
Em profundo desrespeito com o social e os direitos humanos, os empresários deste setor juntamente com a falta de comprometimento do governo federal, justificam em suas defesas que a mencionada lei foi extinta pela Constituição Federal por contrariar normas constitucionais e que para o trabalhador ter respaldo fiscalizatório do governo federal a premissa seria a edição de uma nova lei.

A omissão do Estado em não cumprir imposição de lei constitucional, qualifica-se como comportamento revestido da maior gravidade tanto na esfera social quanto política, ofendendo a própria Carta Magna e os direitos que nela se fundam. Não há justificativas à omissão governamental a fim de frustrar e inviabilizar a preservação e o estabelecimento em favor da pessoa e dos cidadãos de condições materiais mínimas de existência.

No ano de 1990, houve a extinção do Instituto de Açúcar e Álcool (IAA) pela Lei 8.029/90 e em razão disso, a fiscalização quanto aos recolhimentos ou aplicações de tais contribuições deixou de ser realizada por parte dos fiscais do extinto IAA.

Ao contrário do que pode parecer em um primeiro momento, a Lei 4.870/65 não foi revogada, estando plenamente em vigor e, portanto não contrariando os dispositivos da Carta Magna.

O fato é que a assistência social praticada no setor sucroalcooleiro não condiz com o modelo preconizado por esta lei, e que a execução de eventuais planos não é acompanhada pelo governo federal.

A obrigação pleiteada e disposta nos artigos supra mencionados da referida lei possui caráter de direito social, recepcionando-os a Carta Maior.

Em análise a Constituição Federal em seu artigo $7^{\circ}$ que consagra os direitos sociais, direitos de segunda geração na tão propalada classificação dos direitos humanos, não há como os dispositivos da lei 4.870/65 ser contrário às normas preceituadas na Magna Carta e ser extinto sob a falácia de contrariar preceito constitucional. Os direitos sociais têm natureza jurídica de cláusulas pétreas não podendo ser revogados sequer por emenda à Constituição.

O Plano de Assistência Social impõe obrigação de fazer aos seus destinatários, consistentes na elaboração e execução concreta de um plano de assistência médica, hospitalar, farmacêutica e social em benefício dos trabalhadores industriais e agrícolas das usinas, destilarias e fornecedores em prol dos direitos sociais dos trabalhadores.

R. Inter. Interdisc. INTERthesis, Florianópolis, v.5, p.1-28, jan./jul. 2008. 
A contribuição ao PAS (Programa de Assistência Social) prevista na lei 4.870/65 destinada aos trabalhadores da indústria canavieira foi recepcionada pelo artigo $7^{\circ}$, caput, da Constituição Federal de 1988, como direito social.

O artigo prevê que "são direitos dos trabalhadores urbanos e rurais, além de outros que visem à melhoria de sua condição social", regra meramente exemplificativa e não taxativa, portanto admitindo outros direitos sociais em favor dos trabalhadores rurais.

De acordo com Sachs apud Diamond (2004, p. 52) ao sugerir sobre uma maior reflexão quanto a harmonizar os aspectos sociais, ambientais e econômicos diz que:

\footnotetext{
Para compatibilizar os objetivos sociais, econômicos e ambientais, temos que nos dedicar ao que chamaria de um jogo de harmonização. Neste jogo, temos que mudar, por um lado, os padrões da demanda e, por outro lado, os padrões da oferta. Estes últimos são mais fáceis de manejar e vão nos remeter ao problema dos recursos naturais, aos tipos de energia, às tecnologias e á localização espacial das produções, porque as mesmas produções têm impactos ambientais diferenciados, segundo o lugar onde elas acontecem.

A mudança do padrão da demanda é logicamente a variável mais importante nesse jogo de harmonização, porém, ela passa pela modificação dos estilos de vida e dos padrões de consumo, assim é uma variável extremamente difícil de se manipular e exige antes um enorme esforço de educação. As margens de manobra seriam muito maiores se estivéssemos vivendo num mundo mais igualitário.
}

Deste modo, não tratamos nestas análises de subestimar a prática econômica, mas apenas aclarar no que tange à garantia dos direitos sociais dos trabalhadores deste setor, buscando a coexistência do desenvolvimento econômico com a proteção social dos mesmos, que historicamente sempre foram espoliados em nome do desenvolvimento econômico, bem como aliá-lo com sustentabilidade ambiental que constituem temas importantes e fundamentais, emergindo como ferramentas facilitadoras para a tão almejada abertura de mercados.

\section{CONSIDERAÇÕES FINAIS}

Com base nas análises realizadas no presente artigo, observamos a importância das inovações tecnológicas para a economia de um país, capazes de transformar a realidade econômica e social com perspectivas de elevação na competitividade e

R. Inter. Interdisc. INTERthesis, Florianópolis, v.5, p.1-28, jan./jul. 2008. 
produtividade das empresas no âmbito interno e externo bem como gerar melhoria da qualidade de vida para a sociedade em geral.

O Brasil concentra fatores propícios para um melhor desempenho tecnológico/científico no cenário internacional, com um parque industrial diversificado, infra-estrutura de base científica e tecnológica respeitável, mas ainda não emplacou de maneira satisfatória na competitividade dos mercados externos.

Primeiro porque ainda conservamos o ranço das décadas passadas quanto à cultura de importação de tecnologia. Depois, os instrumentos de políticas públicas são insatisfatórios e inflexíveis para entusiasmarem os setores inventivo e produtivo nacional.

Há um profundo descompasso entre empresas e universidades, poucos recursos direcionada à $P \& D$, limitada concentração de recursos humanos capacitados e direcionados a prospectar inovações, seja nos centros de pesquisas, seja nas empresas.

Escassa cultura de propriedade intelectual, com números reduzidos de patentes, incentivos fiscais insuficientes capazes de fomentar e comercializar a inovação.

Carência de articulação entre agências de fomento, institutos de pesquisa e órgãos públicos inexistindo uma política concreta para reorientar a tecnologia e administrar os riscos.

Portanto há necessidade de políticas públicas claras e eficazes com maior comprometimento com intuito de servir de sustentáculo a todos os setores envolvidos para fazer com que o país saia da marginalidade tecnológica e consiga competir com igualdade no cenário internacional.

O abismo tecnológico brasileiro vem somado aos impactos ambientais e sociais devido à cultura predominante de desenvolver economicamente mesmo devastando e degradando o meio ambiente como também marginalizando cidadãos menos privilegiados pelo sistema capitalista.

O caso do setor sucroalcooleiro que muito embora contribua para o progresso e desenvolvimento econômico do país, seja na produção de biocombustíveis seja na geração de empregos, não vislumbra adequadamente os aspectos ambientais e sociais em sua cadeia produtiva. O tão almejado objetivo de aliar desenvolvimento econômico com o meio ambiente para que haja reciprocidade, não foi alcançado por esta atividade.

As formas predatórias da monocultura canavieira continuam provocando os êxodos rurais, degradando biomas importantes, contaminando solos e lençóis freáticos pelo uso 
desmedido do vinhoto. Desrespeita os limites adequados em lei como também ignora o estatuído pelo PAS aos trabalhadores canavieiros e normas como a NR-31 (que regulamenta o trabalho no campo), deixando-os a margem de seus direitos sociais entre outros fatores que poderão ser objeto de estudo nas próximas pesquisas.

Este padrão de desenvolvimento exige maior reflexão sobre os limites da natureza e o quanto é necessário desenvolver, mas sempre na busca de conciliar o desenvolvimento socioeconômico e ambiental em constante sinergia.

Apesar deste setor ter sofrido mudanças significativas no decorrer dos últimos trinta anos, os processos e etapas produtivas ainda acarretam impactos ambientais e sociais negativos, principalmente porque os fatores terra e mão de obra são premissas fundamentais para a dinamização de suas indústrias.

Mendes (2008, p.44) relata que enquanto a agroindústria brasileira de cana aparece na vanguarda tecnológica, capaz de abastecer um país de dimensões geográficas enormes com um combustível limpo e renovável, de outro lado, contribui para manter relações de trabalho ultrapassadas e degradantes.

Este setor possui uma dupla contraditória fisionomia: de um lado há modernizações em tecnológicas físicas nas indústrias e de outro, há um sistema arcaico das tecnologias sociais.

Em setembro do ano passado através da pesquisa denominada "Sustentabilidade Corporativa no Setor Sucroalcooleiro Brasileiro" realizada pela FBDS - Fundação Brasileira para o Desenvolvimento Sustentável, apontou os danos provocados pelo uso intermediário nas relações entre produtores e empregados, advindo deste modelo, aliciamentos irregulares, empregos de baixa qualidade e trabalhos forçados.

O Instituto Ethos de São Paulo (2007) ao pesquisar o setor avaliou que o padrão do mercado brasileiro na qualidade de gestão corporativa obteve resultados acima da média, mas o quadro se transforma nas avaliações sociais e ambientais.

Nos anos vindouros o setor agroindustrial deverá fornecer garantias de produção sustentável e transparente se quiserem continuar competitivos perante as comunidades internacionais que exigem regras claras e desenvolvimento com sustentabilidade, vez que o país está dependendo cada vez mais da demanda externa.

A abertura de mercado, negociações internacionais, gestão da imagem dos produtos brasileiros, gestão sócio-ambiental, são temas gestacionais no país e mesmo 
que premidos por pressões internacionais e não por iniciativas próprias para se modernizarem, merecem ser repensados e reestruturados com o fito no mercado internacional.

O futuro não é algo a ser esperado, mas construído com estratégias eficientes, consistentes e autônomas, não podemos ficar deitados em berços esplêndidos.

A razão capitalista com base na lógica de acumulação do capital está conduzindo nosso planeta para uma situação catastrófica do ponto de vista ambiental e das condições e sobrevivência da humanidade em geral.

"Necessitamos analisar o que existe por detrás do óbvio, o país não pode perder o "bonde" da história.

\section{REFERÊNCIAS}

ALTVATER, E. (1995). O preço da riqueza. São Paulo: UNESP.

BARONI, M (1992). Ambigüidades e deficiências do conceito de desenvolvimento sustentável. Revista de Administração de Empresas, São Paulo: FGV, n.32.

BRASIL. Constituição da República Federativa do Brasil. MORAIS A. (org.) (2007). São Paulo: Manuais de Legislação Atlas.

BOISOT, M.H. (1998). O valor dos Bens Físicos vs. Bens Informacionais (Intangíveis). Oxford: Oxford University Press, p.83.

Cl - Conservação Internacional (Brasil) (2004). Estimativas de perda de área do Cerrado brasileiro. Brasília.

CMMAD-Comissão Mundial sobre o Meio Ambiente e Desenvolvimento. (1991). Nosso futuro comum. Rio de Janeiro: FGV.

DIAMOND, J.(2004) Experiências internacionais de um cientista inquieto: Entrevista com Ignacy Sachs. Estudos Avançados. São Paulo: IEA-USP, 2004.

DOSI, G. (1988). The nature of the innovative process. In: DOSI et al. Technological change and economic theory. Londres: Pinter Publishers.

FERREIRA, E.T. (2006). A queimada da cana e seu impacto socioambiental. Agência de Informação Frei Tito para a América Latina.

FBDS - Fundação Brasileira para o Desenvolvimento Sustentável apud Mendes A (2007/08). Revista Bimestral de Economia e Negócios Internacionais. São Paulo: Totum, dez/jan.

FURTADO, A. T. et al. (1992). Capacitação tecnológica e competitividade: uma abordagem setorial e por empresas líderes (Setor Sucroalcooleiro). Campinas: Unicamp.

R. Inter. Interdisc. INTERthesis, Florianópolis, v.5, p.1-28, jan./jul. 2008. 
FUSER, I. O Etanol e o verde enganador (2007). Le Monde Diplomatique-Brasil, ano 1, n. 5, dez/2007.

INSTITUTO ETHOS apud MENDES, A. (2007/08). Revista Bimestral de Economia e Negócios Internacionais. São Paulo: Totum, dez/jan.

ISPN-Instituto Sociedade, População e Natureza (2008). Cna de açúcar avança em áreas prioritárias para a conservação e uso sustentável do Cerrado. Disponível em: http:// www.ispn.org.br. Acesso em: 22 de janeiro de 2008.

JUNQUEIRA, C. (2007/08). Voto de migrante afeta disputa eleitoral no pólo do etanol. Jornal Valor Econômico, São Paulo, dez/jan. 2007/08. Caderno Opinião, p. A-16.

MAGALHAES, J.P. A; KUPERMAN, N; MACHADO, R. C (1991). Proálcool: Uma avaliação global. Rio de Janeiro: Xérox Editora e Produtora Cultural.

MELLO, C. D. A. (2000). Curso de Direito Internacional Público. Rio de Janeiro: Renovar.

MENDES, A (dez/jan. 2007/08). O atraso da vanguarda. Revista PIB - Presença Internacional do Brasil. Revista Bimestral de Economia e Negócios Internacionais. São Paulo: Editora Totum.

PORTER, M.E (1998). The competitive advantage of nations. Havard. Boston: Business Review.

PRINCEWATER HOUSE COOPERS apud TROSTER, R.L. (2008). O deslumbramento com o bom desempenho esconde deficiências de longo prazo. Jornal Valor Econômico, São Paulo, jan. 2008. Caderno Opinião.

SACHS, J.D. (2006). Technological solutions not political changes, key to ending African Poverty. Project Sindicale, Daily Yomuiri.

SCHUMPETER, Joseph A (1982). A Teoria do desenvolvimento econômico. São Paulo: Abril Cultural. . Capitalismo, Sociedade e Democracia. São Paulo: Abril Cultural, 1988.

STEFFEN, P. G; YOUNG, C.E.F. (2008) Conseqüências econômicas das mudanças climáticas. Disponível:: $w$ ww.comciencia.br/comciencia/?section $=8 \&$ edicao $=22 \&=236$. Acesso em: 03 de janeiro de 2008.

SZMRECSANYI, T. (1994). Tecnologia e degradação ambiental: O caso da agroindústria canavieira no Estado de São Paulo. Revista Informações Econômicas, São Paulo, v. 24, n.10.

TOFFLER, A. (2007) A riqueza revolucionária. São Paulo: Futura.

TROSTER. R.L.(2008) O deslumbramento com o bom desempenho esconde deficiências de longo prazo. Jornal Valor Econômico, São Paulo, jan.2008. Caderno Opinião.

WORLD ECONOMIC FORUM-WEF, 2006/2007 apud NETTO A.D. O setor público e o privado. Jornal Valor Econômico, São Paulo, dez. 2007. Caderno Opinião.

Artigo submetido em 16 de fevereiro de 2008. Artigo aceito em 20 de Junho de 2008.

R. Inter. Interdisc. INTERthesis, Florianópolis, v.5, p.1-28, jan./jul. 2008. 